\title{
Massagem com bebês: pesquisando estratégias de empoderamento
}

\author{
Massage with babies: researching empowerment strategies
}

Masaje en bebés: investigando estrategias de empoderamiento

\author{
Maria das Graças Barreto da Silva ${ }^{1}$; Vitória Helena CunHa EsPósito ${ }^{2}$ \\ Universidade Federal de São Paulo, UNIFESP, São Paulo-SP, Brasil \\ Pontifícia Universidade Católica de São Paulo, PUC-SP, São Paulo-SP, Brasil
}

\begin{abstract}
RESUMO
Como profissionais voltadas às questões do cuidar e educar na primeira infância, nos identificamos com as premissas do fazer docente assumindo responsabilidade pela formação a partir da intervenção na realidade social, por meio da extensão. Tematizamos a Oficina de massagem com bebês, uma das ações pedagógicas do programa de extensão Massagem e Estimulação com Bebês (MEB), e percorremos uma trajetória fenomenológico-hermenêutica, com o objetivo de compreender os sentidos da experiência vivenciada por doze profissionais e uma estudante, em resposta à pergunta: Como foi sua experiência na Oficina de Massagem com Bebês? Com as categorias manifestas, trazemos, como foco deste trabalho: A contribuição à construção do vínculo mãe/pai-filho e profissionais cuidadores, desvelada na experiência da Oficina como estratégia de empoderamento social dos profissionais junto aos familiares.
\end{abstract}

Palavras-chave: Educação. Enfermagem Pediátrica. Pesquisa Qualitativa. Massagem. Desenvolvimento Humano.

\begin{abstract}
As professionals focused on issues of care and education in early childhood, we are identified with the premises of teaching as a factor responsible for the formation through the intervention in social reality, by means of extension. Our subject is the Baby Massage Workshop, one of the pedagogical actions of the Massage and Stimulation with Babies (MEB) extension program, and we follow a phenomenological-hermeneutic trajectory, with the objective of understanding the perception of the experiences lived by twelve professionals and a student, in response to the question: How was your experience at the Massage Workshop with Babies? With the categories made explicit, we bring, as the focus of this work: The contribution to the construction of the mother/father-child bond and professional caregivers, unveiled in the experience of the Workshop as a strategy for the social empowerment of the professionals along with the family members.
\end{abstract}

Keywords: Education. Pediatric Nursing. Qualitative Research. Massage. Human Development.

\section{RESUMEN}

Como profesionales orientadas a las cuestiones del cuidar y educar en la primera infancia, nos identificamos con las premisas del quehacer docente, asumiendo responsabilidad en la formación a partir de la intervención en la realidad social, mediante la extensión. Tematizamos el Taller de Masaje en Bebés, una de las acciones pedagógicas del programa de extensión Masaje y Estimulación en Bebés (MEB), y realizamos una trayectoria fenomenológico-hermenéutica, apuntando a comprender los sentidos de la experiencia vivida por doce profesionales y una estudiante, respondiendo a la pregunta: ¿Cómo fue su experiencia en el Taller de Masajes en Bebés? Con las categorías manifiestas, ofrecemos, como foco del trabajo: La contribución a la construcción del vínculo madre-/padre-hijo y profesionales cuidadores, revelada en la experiencia del Taller como estrategia de empoderamiento social de los profesionales conjuntamente con los familiares.

Palabras clave: Educación. Enfermería Pediátrica. Investigación Cualitativa. Masaje; Desarrollo Humano.

\footnotetext{
${ }^{1}$ Professora da Escola Paulista de Enfermagem da UNIFESP. E-mail: silva.barreto@ unifesp.br

${ }^{2}$ Professora Titular da PUC-SP. E-mail: vitoriaesposito@ hotmail.com
} 


\section{INTRODUÇÃO}

Como profissionais voltadas às questões do cuidar e educar na primeira infância, percebemos cada vez mais o crescente interesse das mães e pais em descobrir como cuidar e favorecer o desenvolvimento dos seus filhos, assim como acalmá-los (SILVA et al., 2015). É visível como as relações familiares podem ser favorecidas quando encontramos oportunidades de demonstrar as competências e capacidades dos bebês, desde o início da vida, enfocando-os como seres humanos capazes de se relacionar com o ambiente e com as pessoas de inúmeras formas, em seus aspectos fisiológicos e psicológicos próprios (SILVA; ESPÓSITO, 2011). Nesta configuração é que se coloca a massagem com bebês como um saber culturalmente expressivo, que veio sendo ressignificado historicamente e propiciou que introduzíssemos na UNIFESP, na década de 90, um trabalho com abordagem corporal, ancorado nas premissas do desenvolvimento infantil, realizado de maneira sistematizada, a fim de responder a essa necessidade emergente da população, ampliando fronteiras. À época - como ainda hoje - era frequente observarmos as dificuldades que algumas famílias sentiam em compreender o comportamento dos bebês.

Por outro lado, a constância com que os profissionais, em nosso meio, procuram destacar as suas insatisfações com o que geralmente ocorre nas instituições - de saúde e educação infantil - onde as expressões do bebê não são utilizadas como estratégias para cuidá-lo, suscita a necessidade de abordagens mais frequentes voltadas ao conhecimento do desenvolvimento infantil, com a ampliação e diversificação de pesquisas.

Observe-se que a Organização Mundial da Saúde (OMS), por meio do Programa de Medicina Tradicional, vem há anos estimulando as Práticas Integrativas e Complementares (PICs). O Programa, que também busca desenvolver estudos para conferir a eficácia, segurança e qualidade das PICs em saúde, inclui a massagem para bebês, referida como "Shantala". Em decorrência desses esforços, a OMS elabora um documento normativo com vistas ao fortalecimento de políticas para a utilização racional e integrada das terapias não convencionais nos sistemas nacionais de atenção à saúde (WHO, 2004).

Ressalta-se que no Brasil também existe, há tempos, uma crescente busca pela legitimação da abordagem terapêutica holística. Como consequência, em 2006, o Ministério da Saúde publicou a Portaria $n^{\circ}$ 971, que aprovou a denominada Política Nacional de Práticas Integrativas e Complementares (PNPIC) como abordagem de cuidado no Sistema Único de Saúde (SUS). Essa portaria traçou as diretrizes e responsabilidades para a implantação das suas ações e serviços em território nacional (FONTANELLA et al., 2007). Mais recentemente, em março de 2017, com a publicação da Portaria no 849, o Ministério da Saúde (BRASIL, 2017) ampliou as PICs, que fazem parte da PNPIC, incluindo a Shantala, que foi assim descrita:

[...] é uma prática de massagem para bebês e crianças, composta por uma série de movimentos pelo corpo, que permite o despertar e a ampliação do vínculo cuidador-bebê. Promove a saúde integral, reforçando vínculos afetivos, a cooperação, a confiança, criatividade, segurança, equilíbrio físico e emocional. Promove e fortalece o vínculo afetivo, harmoniza e equilibra os sistemas imunológico, respiratório, digestivo, circulatório e linfático. Permite ainda ao bebê e à criança a estimulação das articulações e da musculatura, auxiliando significativamente no desenvolvimento motor, facilitando movimentos como rolar, sentar, engatinhar e andar (p. 68).

Sem dúvida, a publicação da portaria foi uma conquista para a saúde pública, e a crescente demanda pelas PICs vem sendo acompanhada de um alerta sobre a 
necessidade de um diagnóstico para cada população, como meio de concretizar as estratégias de promoção do acesso (FONTANELLA et al., 2007).

$\mathrm{Na}$ esteira desta busca é que nos reportamos ao trabalho desenvolvido por Silva (2017), "Os sentidos das experiências vividas no programa de extensão massagem e estimulação com bebês", considerando também o pensamento de Espósito (2006), ao colocar que o processo de conhecimento se dá a partir de um certo lugar: o mundo da criança como o enfocamos aqui, em situação. Lembramos ainda, como Cunha (1997), que a preocupação e mesmo a interpretação dos sentidos do conhecimento sobre a criança se colocam conforme as concepções que suportam a visão de mundo, de homem, de sociedade, de educação daquele que, como sujeito, interroga.

Nessa perspectiva é que emergiu a motivação para a realização do presente estudo, na procura por consolidar os fazeres, já configurados em um Programa de extensão universitária: "Massagem e Estimulação com Bebês" (MEB).

\section{O Programa de extensão universitária Massagem e Estimulação com BEBÊS (MEB)}

O MEB é composto por ações integradas que se organizam em três pilares: 1. Oficina de massagem com bebês, disponibilizada a graduandos e profissionais das áreas de saúde e educação infantil, com assessorias a serviços institucionais; 2. Grupo terapêutico de massagem e estimulação com bebês (GTMEB), destinado às mães/pais com seus filhos, e que recebe também estudantes e profissionais; 3. Grupo de estudo massagem e estimulação com bebês (GEMEB), coordenado pelas(os) graduandas(os) extensionistas da instituição. Observe-se que a difusão do conhecimento produzido por meio das ações desenvolvidas no Programa de extensão MEB vem sendo sistematicamente apresentada à comunidade científica, sendo este trabalho parte desta construção (SILVA; ESPÓSITO, 2017; TAVARES et al., 2016).

Mais ainda, as experiências vividas nesses anos nas ações do Programa de extensão MEB, assim como a literatura sobre a massagem (NARDO; SILVA; MARIN, 2014), demonstram que a procura por esse tipo de intervenção está ganhando adeptos e cada vez mais se difunde seu uso terapêutico. Contudo, nas Oficinas, por meio de uma conjunção de saberes, vivências e reflexões, temos buscado tornar esses conhecimentos acessíveis a profissionais e estudantes das áreas da saúde e educação infantil, e almejamos que, à medida que estes se tornem conscientes da qualidade do toque nos cuidados, assim como da importância da intervenção mediada pela massagem e seus efeitos sobre o desenvolvimento integral do bebê, tenhamos essa atividade reconhecida pelos seus benefícios, como parte essencial do rol de cuidados que chamamos de maternagem $^{3}$.

No desenvolvimento deste percurso guiou-nos a responsabilidade social da academia na formação dos profissionais da saúde e da educação para o cuidar humanizado $^{4}$, e é por meio dele que visamos contribuir para a melhoria dos serviços como partícipes de políticas públicas orientadas à primeira infância, unindo esforços para que a lei que especifica a relevância da atenção ao desenvolvimento infantil (BRASIL, 2016) possa ser expressa em ações.

\footnotetext{
${ }^{3}$ Maternagem: refere-se a um sistema de cuidados prestados pela mãe ou um adulto responsável por exercer esta função, para suprir as necessidades dos bebês (LA PLANCHE, 1992).

${ }^{4}$ A humanização representa um conjunto de iniciativas que visa à produção de cuidados em saúde capazes de conciliar a tecnologia disponível com promoção de acolhimento e respeito ético cultural ao paciente, de espaços favoráveis ao bom exercício técnico e à satisfação dos profissionais de saúde e usuários (PUCCINI; CECÍLIO, 2004).
} 
A enfermagem, assim como a educação, pode se beneficiar com a amplitude do cuidado com o ser humano, considerando-se este enquanto ser situado existencialmente no mundo, indicando que nosso estudo não deveria se restringir apenas aos seus aspectos tecno-científicos. Foi assim que destacamos para esta investigação a fenomenologia e, em particular, a fenomenologia existencial e hermenêutica, por permitir um olhar qualificado sobre as ações educativas desenvolvidas no Programa de extensão MEB.

\section{DIZENDO DA METODOLOGIA DO TRABALHO}

Esta pesquisa, ao se iluminar compreensivamente, intencionou deixar ver como se mostra o trabalho desenvolvido no Programa de extensão MEB, e dessa forma dispôs-se a apreender os sentidos de sua construção para aqueles que vivenciam suas ações; tendo presente que as premissas da fenomenologia indicam que a busca por compreender os seres humanos em sua complexidade, como seres situados no mundo com os outros, nos permite abordá-los em um horizonte de perspectivas (ESPÓSITO, 2011).

Sistematizada no espaço das Oficinas, das aulas teóricas, técnicas e práticas realizadas com estudantes e profissionais, esta ação, ao ser assim desenvolvida e refletida, vem possibilitando a construção desta trajetória metodológica. Neste envolvimento e com o objetivo de compreender os sentidos das experiências ali vividas, fomos guiadas pela pergunta: Como foi sua experiência na Oficina de Massagem com Bebês?

Nesta trajetória nos apoiamos em autores como Heidegger (1998) e Ricouer (1988), assim como pensadores contemporâneos representados por van Manen (2003) no Canadá e, no Brasil, Martins (1992), Freire (1959), Espósito (2016), Bicudo e Espósito (1997), Silva e Espósito (2011) e Tafuri e Gonçalves Junior (2017), cada um deles com o seu estilo de fazer fenomenologia, influenciados pelo rigor metodológico próprio a esta forma de investigar. Observamos ainda que com Heidegger (1998) é que ocorre a inserção da fenomenologia na hermenêutica, colocando como central ao inquérito o ser na sua existência, a ontologia, isto é, o Ser concebido como tendo uma característica comum, inerente a todos e a cada um dos seres. Desse modo, essa fenomenologia passa a fundamentar-se na compreensão e interpretação de como as coisas se manifestam ao tornar visível a estrutura do ser no mundo (ESPÓSITO, 2001), e em especial na compreensão dos sentidos das experiências vividas na Oficina de Massagem com Bebês.

\section{REGIÃO DE INQUÉRITO/ OS SUJEITOS / DISCURSOS/TRATAMENTO METODOLÓGICO}

O projeto aprovado pelo Comitê de Ética em Pesquisa da UNIFESP, sob o Parecer $n^{\circ}$ 1.424.084, obedeceu aos preceitos éticos emanados da Resolução no 466, de 12 de dezembro de 2012, do Conselho Nacional de Saúde (BRASIL, 2012).

Por solicitação da coordenação do Programa de Promoção da Saúde - Núcleo de Práticas Integrativas e Complementares - Departamento de Políticas de Saúde da Secretaria Municipal de Saúde, em 2014, ministramos cinco Oficinas de Massagem com Bebês na cidade de São José dos Campos/São Paulo. Participaram dessas Oficinas profissionais da saúde e graduandos de enfermagem, com a finalidade de formar multiplicadores para atuarem com a massagem interligada aos trabalhos por eles já efetivados nos grupos com gestantes e de puericultura. Visamos com isso implantar ações do GTMEB na rotina de cuidados em saúde materno-infantil, já realizadas pela 
rede de atenção básica e secundária nas Unidades Básicas de Saúde (UBS) e na Unidade Casulo do Centro de Lactação (NASR et al., 2018).

Essa trajetória metodológica incluiu a forma como acessamos as descrições dos sujeitos, sendo intrinsecamente ligada à região de inquérito, nos dizendo da situacionalidade dos mesmos: refere-se "[...] aos elementos responsáveis pela pertinência e relevância do texto quanto ao contexto em que ocorre; diz da adequação do texto à situação sociocomunicativa" (VAL, 2006, p. 12).

Denominadas Oficinas I, II, III, IV e V, destacamos que as descrições fenomenológicas foram coletadas pela pesquisadora ao final de cada uma, momento em que os participantes descreviam suas vivências em resposta à pergunta da pesquisa. Escolhemos a Oficina V de maneira aleatória, e o critério de inclusão das descrições dos doze profissionais e de uma estudante - sujeitos da pesquisa - esteve relacionado às suas participações em seus dois módulos, tendo-a como região de inquérito.

Observamos que na pesquisa qualitativa o estudo se encerra quando por meio dos significados expressos encontramos conteúdos suficientes para a compreensão das estruturas essenciais, não requerendo um número determinado de participantes (MARTINS; BICUDO, 1994).

Seguindo na trajetória da pesquisa, lendo atentamente as descrições, buscamos ver com os olhos dos participantes da Oficina V, sem qualquer julgamento, procurando manter em suspensão as opiniões, pressupostos e interpretações, focando a experiência por eles vivida, os significados relevantes que caracterizassem o fenômeno (MARTINS, 1992).

Lembramos que a compreensão se dá por meio do sentido que surge como resultado da redução fenomenológica, sendo assumida como um conjunto de asserções significativas denominadas unidades de significado (US), que ao responder à pergunta posta apontam para a consciência que o pesquisador tem do fenômeno (MARTINS; BICUDO, 1994).

Com a preocupação de que as US espelhassem certas dimensões do contexto, seguindo com o apoio do léxico, após inúmeras leituras das diferentes descrições (D) dos treze sujeitos participantes da Oficina V - identificadas de DI a DXIII procedemos à primeira redução fenomenológica. Das treze descrições analisadas elegemos cinquenta e nove US, em resposta à pergunta da pesquisa e ao organizar uma síntese delas - agora abertas à interpretação. Com a segunda redução visualizamos quinze temáticas que dizem dos elementos essenciais do fenômeno, que assim se expressaram: Teoria-técnica-prática, aprendizagem, didática, estratégia metodológica, perspectiva interdisciplinar, propósito, expectativa, descoberta, despertar, falta, congratulação, satisfação, cuidado, avaliação, agradecimento. Buscando explicitar suas convergências, em virtude de seus imbricamentos, simultaneamente procuramos perfazer uma textura, o que nos encaminhou à reorganização de três grandes categorias - ao procedermos a uma terceira redução - que assim se anunciaram: (1) Apoio à formação profissional humanizada. Teoria, técnica, prática: Diálogos, (2) Contribuição à construção do vínculo mãelpai-filho e profissionais cuidadores e (3) Tempo vivido na experiência da Oficina do MEB: desvelando sentidos. Entretanto, para este trabalho trazemos a categoria (2), que passamos a apresentar.

\section{CONTRIbUição À CONSTRUÇÃo do VÍNCUlo MÃE/PAI-FILHO E PROFISSIONAIS CUIDADORES. A PESQUISA PROPRIAMENTE DITA}

Essa categoria é resultante da confluência das temáticas propósito, expectativa, descoberta, despertar e cuidado, onde os participantes da Oficina - sujeitos da pesquisa 
- demonstram compreender o horizonte do trabalho do Programa de extensão MEB, no qual apreendem determinadas imagens de mundo. Essas imagens, ao serem capturadas como fenômenos, são intuídas, sentidas e percebidas de forma singular, como possibilidade de desdobramentos também para suas atuações profissionais.

A partir das experiências vivenciadas na Oficina, observamos como os profissionais - sujeitos ${ }^{5}$ da pesquisa - expressam seus propósitos considerando os sentidos que o léxico nos abre, a fim de registrar as significações que foram atribuídas a cada signo ao longo da história humana, com as seguintes possibilidades interpretativas: Do léxico trazemos a palavra propósito, do latim propositu, significando intenção de fazer alguma coisa, decisão, resolução (WEIZZFLOG, 2004).

Percebemos pela descrição do profissional, na sequência, que ele encontra na massagem a possibilidade de apoio às famílias que estão com dificuldades em se relacionar com seus filhos: [...] através deste aprendizado estarei ensinando (DIII.US.3) e ajudando alguém a correr atrás do prejuízo (DIII.US.3.1), ajudando nossas crianças a serem amadas, (DII.US.3.2) e mais tarde saber dar amor (DII.US.3.3). Assim, ao expor seu propósito, como intenção de atuar profissionalmente utilizando os conhecimentos compartilhados, como forma de minimizar danos, acredita que poderá agir como facilitador para que as crianças sejam cuidadas com afeição e, no futuro, venham a ser, venham a se tornar seres amorosos.

Em outra descrição encontramos as palavras do sujeito referido anteriormente, que já havia integrado as ações do MEB: Uma ferramenta para melhorar o vínculo mãe $e$ filho (DIX.US.2), e com isso melhorar também as áreas de cuidado (DIX.US.2.1). Fazia algum tempo que eu havia visto sessões de massagem [GTMEB] e participado do grupo [GEMEB], (DVII. US.1) [...] foi como a retomada de algo que gosto muito, que me faz muito bem (DVII. US.1.1).

Destacamos no relato acima que o fato de "participar novamente" - em outro tempo - da Oficina foi um reencontro de um sentido que encanta e agrada ao sujeito. Como veremos, ele prossegue, enfatizando que assimilou - o que foi exaustivamente reiterado na Oficina - a necessidade de estimular o relacionamento do profissional não só com o bebê, para conhecê-lo, mas também com sua família, por acreditar que a qualidade dessas relações contribuirá para a saúde da criança, como descrito a seguir: $E$ muito importante a sensibilização do profissional que fica tanto tempo com a criança (DVII.US.3) e principalmente entender como o vínculo mãe-pai-bebê e mãe-pai-bebê e profissional é importante para a recuperação (DVII.US.3.1).

Reiteradas vezes os profissionais participantes da Oficina, ao demonstrarem que estão atraídos pelo tema, expressam anseio em estudá-lo a fundo e solicitam mais bibliografia além daquela já disponibilizada, pois para muitos a temática se apresenta como novidade. Isso pode ser visto na descrição a seguir, em que o sujeito indica a descoberta da massagem, cuja existência lhe era desconhecida: [...] uma técnica de terapia complementar que não conhecia a fundo (DV.US.2).

Retomando no léxico o significado de despertar, encontramos: dar ocasião a (WEIZZFLOG, 2004), que, pela descrição do profissional, o remeteu a questões da sua vida pessoal: [...] me fez analisar até mesmo minhas dúvidas na criação e no desenvolvimento dos meus filhos [...] (DII.US.1.2).

Em outra descrição, a profissional declara que a Oficina a despertou, no sentido de ter propiciado ocasião (WEIZZFLOG, 2004) para que ela voltasse sua atenção e

\footnotetext{
5 Observe-se que no texto as descrições dos sujeitos estão em itálico e identificadas pelo Discurso (D), acompanhados pelos números cardinais romanos, seguidos pelos números cardinais arábicos que indicam as unidades de significado (US).
} 
refletisse sobre seu ambiente de trabalho: [...] [me fez analisar minhas dúvidas] [e] no meu ambiente profissional (DII.US.2).

Observamos também a preocupação de uma estudante, sujeito desta pesquisa, que está atualmente experienciando o aprendizado na Unidade de Terapia Intensiva Neonatal (UTIN), ao advertir sobre a falta que faz um olhar atento ao bebê que decodifique e atenda às suas necessidades, como colocado na US a seguir: Agora estagiando na UTI Neo (DVII. US.2), vejo como o bebê não é respeitado em suas vontades e muitas vezes não é compreendido no comportamental (DVII. US.2.1).

A UTIN possibilita cuidados aos bebês (LLAGUNO et al., 2016) que necessitam, muitas vezes, de terapêuticas clínicas complexas, em um ambiente repleto de estímulos. Em nossa realidade, a humanização do cuidado neonatal ${ }^{6}$, voltada ao desenvolvimento integral do bebê, vem sendo inserida gradativamente nessas unidades (SBP, 2003). Embora essas ações possibilitem, aos poucos, explorar os aspectos que remetem ao cuidado com o desenvolvimento integral do recém-nascido e promovam sua continuidade, levando o profissional a identificar e demonstrar os momentos de disponibilidade do bebê sem sobrecarregá-lo, as equipes ainda estão voltadas principalmente para as questões técnicas, o que significa extrair do bebê a possibilidade de arremessar-se à conquista da condição e da capacidade de participação, em conformidade com o léxico, ou seja, de seu empoderamento (WEIZZFLOG, 2004).

Nesse panorama, mudanças de atitudes necessitam de tempo para se consolidar, solicitando investigações a partir de experiências em contextos que privilegiem a humanização (LLAGUNO et al., 2016; SBP, 2003).

$\mathrm{Na}$ sequência, o sujeito indica que compreendeu como a abordagem apresentada na Oficina possibilita uma descoberta, que o léxico aponta também como solução conveniente (WEIZZFLOG, 2004), e que a fala expressa como possibilidade de apoiar as famílias que encontrem dificuldades em se relacionar com os filhos pequenos, ou mesmo que apresentem problemas: [...] vai ser uma ferramenta a mais $p /$ [ob] oferecer aos pacientes (DVI.US.4). [...] para ajudar as crianças com problemas (DVI.US.5.1) que podem ser resolvidos com o toque, [com] a massagem [...] (DVI.US.5.2).

Assim, necessário se faz apontar também para a importância de se construir um corpo de conhecimento a partir das relações do adulto com o bebê, tais como se estabelecem (ESPÓSITO, 2006; LLAGUNO et al., 2016). Encontramos um exemplo, em trabalho realizado anteriormente, com foco na motricidade expressa pelos bebês lactentes em situação de massagem no GTMEB, quando foram desveladas suas competências e necessidades, indicando que o estudante/profissional, ao elevar a importância do sujeito no processo de construção do conhecimento, favoreceu a compreensão do desenvolvimento humano como condição ao inter-relacionamento dialético entre o ser e o mundo (SILVA; ESPÓSITO; OHARA, 2014; SAITO; SILVA; ESPÓSITO, 2009; OLIVEIRA; SILVA, 2003).

Surge daí a necessidade de esclarecimentos quanto à questão: $\mathrm{O}$ que é para nós o empoderamento infantil? O empoderamento é comumente enfatizado na perspectiva da mulher, da mãe, que traz, embora de forma menos discutida, um aspecto voltado ao empoderamento infantil.

\footnotetext{
${ }^{6}$ A humanização do cuidado neonatal é baseada em ações voltadas ao respeito à individualidade e à garantia de tecnologia e permite segurança e acolhimento ao bebê e sua família. Com ênfase no cuidado ao desenvolvimento integral do bebê, considera o seu psiquismo e atua como facilitador no vínculo afetivo com a mãe, desde a permanência hospitalar até após a alta (SBP, 2003).
} 
Como já visto no léxico, utilizamos o termo empoderamento também no sentido da capacidade de participação, que na massagem se traduz como o respeito do adulto às sinalizações dadas pelo querer do bebê; empoderamento este que pode ser desvelado tanto pelos profissionais como pelas mães.

Trabalhos por nós já realizados indicam haver correspondência entre os pares mãe/bebê e estudante/bebê, isto é, a retribuição do bebê à atuação do adulto em situação de massagem. Isto pode ser observado na fala de uma das mães - meu bebê passou cada vez mais a apresentar sinais de receptividade (SAITO; SILVA; ESPÓSITO, 2009; OLIVEIRA; SILVA, 2003); assim como na experiência de uma graduanda ao revelar satisfação pela receptividade do bebê e surpresa diante da competência de suas reações (LLAGUNO et al., 2016). Vemos assim explicitada uma linguagem através da qual o bebê progressivamente objetiva seu corpo e sua ação em correspondência ao corpo e à ação da mãe e/ou de um adulto sensível; é uma comunicação tônico-emocional denominada diálogo tônico-corporal (AJURIAGUERRA, 1985). O conhecimento dessa linguagem propicia perceber a movimentação do bebê em resposta à fala da mãe, quando ela o está massageando, ou mesmo quando ela o está segurando em seus braços ou ainda amamentando e regula a distância entre seus olhos, permitindo que o bebê consiga focalizar o seu rosto, favorecendo uma interação. É uma oportunidade de presenciar momentos de sintonia, de um olhar na perspectiva da presença que vem confirmar a intimidade e empoderar o bebê (SILVA; ESPÓSITO, 2011; SILVA, 2017). Como diz Stern (1992), a expansão do comportamento da mãe para além da imitação é um novo momento na relação que parece ajustar o bebê como parceiro potencialmente subjetivo, que ele chama de sintonia do afeto.

Coloca-se, dessa forma, a descoberta do sentido do empoderamento infantil como uma possibilidade: considerar o bebê como um parceiro, levando em conta seu modo peculiar de se expressar.

Destacamos aqui que, além da compreensão das competências e necessidades dos bebês e para que se atinja um resultado satisfatório com a massagem, não basta apenas aplicá-la ao bebê; é preciso realizá-la "com ele" (GENESI, 2014). Ressaltamos ainda que, para que seja favorecido seu empoderamento, o bebê deverá participar como sujeito da ação, momento em que devemos considerar suas possibilidades de expressão e seus limites, o que poderá repercutir não só na qualidade da relação mãe/pai e filho, mas também ser extensivo à relação do profissional com o bebê e sua família (SILVA, 2017; LLAGUNO et al., 2016).

$\mathrm{Na}$ Oficina, ao compartilharmos trabalhos para reflexões, como os acima citados, buscamos contribuir para que seus participantes, por meio da ampliação de conhecimentos teórico-técnico-práticos, sejam empoderados socialmente.

Nesse sentido, podemos dizer que, nos cenários do Programa de extensão MEB, desvela-se o empoderamento (SILVA, 2017) como a conquista da condição e da capacidade de co-participação dos profissionais e estudantes na dimensão social, para cumprir uma das funções do profissional da saúde, que é também participar do restabelecimento do papel próprio às famílias no cuidado com seus filhos, através do seu empoderamento, contribuindo para a promoção da parentalidade (FMCSV, 2017).

O conceito de parentalidade (FMCSV, 2017) vem ampliar a concepção de maternagem (SILVA et al., 2015); fala sobre as ações realizadas pelos adultos de referência no cuidado da criança, isto é, aqueles que mantêm os laços afetivos no cotidiano, visando assegurar a sua sobrevivência e o seu desenvolvimento integral. Embora esse papel seja frequentemente atribuído aos pais biológicos, pode ser desempenhado por outros adultos que sustentem laços afetivos significativos e cumpram as funções parentais, sendo responsáveis pela criança. 
$\mathrm{Na}$ descrição que segue, o profissional destaca que a massagem é apresentada como um elemento que favorece o reconhecimento do papel social da mãe: $e$ [...] uma forma de valorizar a figura da mãe (DIX.US.3).

Nessa mesma direção, vemos o participante fazer a descoberta de que a realização da massagem pode funcionar como um cuidado, que pode auxiliar no empoderamento das mães que estejam com dificuldades em cuidar de seus filhos, na disposição de se assumirem como sujeitos conscientes de tal decisão: A prática [...] vai com certeza auxiliar as mães que já não sabem o que fazer com seus filhos [...] (DVI.US.3).

Situados nesse espaço-tempo e no movimento das Oficinas, os participantes manifestam abertamente e com espontaneidade o que pensam, expondo suas ideias, apresentando soluções, buscando uma aprendizagem significativa por meio de ações que se mostrem coerentes (SILVA; ESPÓSITO; OHARA, 2014).

Com isso, as Oficinas vêm se configurando, no dizer dos profissionais e estudantes, como experiência que se dá na coexistência ${ }^{7}$, conforme explicitado no agradecimento: Obrigado por ter gente como você (DIII.US.1), que também se importa com gente [formação de pessoas] (DIII.US.1.1).

Mais ainda, nas US apresentadas a seguir, os sujeitos expressam suas expectativas, que no léxico são vistas como a espera de uma realização (WEIZZFLOG, 2004), aqui dirigida a implantar a massagem nas UBS onde atuam profissionalmente e, assim, cooperar com os usuários desse serviço em saúde: Vamos fazer com certeza na UBS (DXIII.US.2); [...] essa técnica simples (DX.US.2) que pode ajudar muito no contato com mãe e filho (DX.US.2.1). Espero desenvolvê-la (DX.US.2.2) e poder colaborar (DX.US.2.3).

Nesse sentido, subsiste nos discursos dos profissionais - sujeitos da pesquisa uma esperança a partir da vivência na Oficina, que já vem sendo correspondida, encaminhando-os para a implantação de GTMEBs, ação esta que vem sendo desenvolvida na rede de atenção básica, na cidade de São José dos Campos, dentro da rotina de cuidados materno-infantis nas UBS onde os profissionais atuam. Entre os anos de 2014 e 2017 foram realizados encontros de matriciamento ${ }^{8}$ nas UBS para 158 funcionários, resultando, até o momento, num total de 253 colaboradores capacitados para atendimento em grupos para mães e bebês de 2 a 7 meses. Essas ações já estão presentes em 23 UBS (57,5\%), resultando em 549 grupos, com atendimento a 1.212 bebês (NASR et al., 2018).

Diante disso, podemos ponderar que há a percepção de um poder ser - ainda que latente e intuitivo - que perpassa toda a vida humana, o que suscita o despertar do sujeito aprendente para a questão política e social que o empoderamento pode provocar.

De acordo com Freire (2003), se faz necessário que a pedagogia esteja pautada pela ética, pelo respeito à dignidade e à própria autonomia do educando, e como docentes estejamos vigilantes contra todas as práticas de desumanização.

Surge então a necessidade de outro esclarecimento, agora, quanto à questão: $\mathrm{O}$ que é para nós o conhecimento intuitivo? Para tanto consideramos que o conhecimento intuitivo: "Inato ao ser humano, [...] diz respeito à subjetividade. Às nossas percepções

\footnotetext{
7 Coexistência, para a fenomenologia, é uma condição ontológica que é dada ao homem na existência; é uma característica estruturante da humanidade dos homens. Somos plurais, isto é, constituídos pelos outros em nosso próprio ser, embora sejamos também singulares, constituídos por nós mesmos (CRITELLI, 2006).

${ }^{8} \mathrm{O}$ matriciamento ou apoio matricial é um novo modo de produzir saúde em que duas ou mais equipes, num processo de construção compartilhada, criam uma proposta de intervenção pedagógico-terapêutica (BRASIL, 2011).
} 
do mundo exterior e à racionalidade humana. Manifesta-se de maneira concreta quando, por exemplo, tem-se uma epifania" (RONDON FILHO, 2010, p. 11).

Desde esse ponto de vista, os profissionais particularmente intuitivos/atenciosos, capazes de compreender os bebês, captam suas necessidades, descobrindo suas formas elementares de interação. Demonstram que, ao cuidá-los humanamente, isto é, considerando a sua subjetividade desde o início, é possível identificá-los como parceiros (SILVA, 2017; LLAGUNO et al., 2016), indicando, desse modo, como a interação reforça o desenvolvimento das capacidades do bebê, explicitadas pela sua participação. A descrição seguinte nos permite visualizar isso: A massagem é um ato de amor (DVII.US.4), um momento de compartilhar experiências com o bebê, entendê-lo $e$ respeitá-lo (DVII.US.4.1).

Considerando que a literatura (BUSNEL, 1997; BRAZELTON, 1992; SHORE, 2000) fornece amplos conhecimentos sobre bebês e que estes podem pautar nossas observações, percepções e, consequentemente, os nossos cuidados, é importante compreender que a intuição, embora enriqueça essas observações e percepções, pode não ser suficiente para guiá-las, tornando-se indispensáveis os saberes produzidos pela ciência.

Salienta-se a importância das ações educativas veiculadas pelas Oficinas, que se mostram como canal de difusão de conhecimento e como estratégia para sensibilizar e conscientizar os responsáveis pelos cuidados para a necessidade de colocar em pauta as interfaces dos cuidados à criança junto à família.

Acreditamos assim que, por meio de uma intervenção oportuna e integradora como a massagem, contribuímos para a promoção da saúde familiar, podendo prevenir agravos à saúde dos bebês através da potencialização dos laços afetivos (SILVA, 2017).

Nessa direção, temos a descrição de um dos sujeitos, apontando a massagem como uma estratégia para favorecer a relação do profissional com a família: [...] [uma forma de] melhorar vínculo com o profissional de saúde (DIX.US.4).

Nesse contexto, fica clara a abertura para a possibilidade de ser-no-mundo que se oferece aos participantes das Oficinas quando a massagem lhes é desocultada por meio do diálogo entre teoria, técnica e prática, assim imbricadas, em uma perspectiva de cuidado humano. Esta, acrescida da compreensão e das vantagens de sua eficácia enquanto intervenção, permite que o conhecimento avance qualitativamente de forma processual e dinâmica.

Pensar o cuidado na perspectiva do desenvolvimento humano nos remete, também, às ações pelas quais cada um é responsável nas relações familiares, sendo que estas primeiras formas de relação vêm matrizar as possibilidades de existência do indivíduo. Isso ocorre na trajetória de humanização, um processo também socialmente construído de forma contínua, inacabado até a finitude, na busca de ser si mesmo, de encontrar-se a si próprio. Nesta direção, como seres humanos, estamos sempre na condição de ser, de nos tornarmos, sendo, vislumbrando horizontes de possibilidades. Como indicado por Espósito (1993), cada conceito, além da diversidade de suas significações e de seus usos em determinadas circunstâncias, pode se abrir a outras considerações, produzindo, além de significações, intersignificações.

\section{INTERSIGNIFICAÇÕES: REFLETINDO SOBRE A EXPERIÊNCIA DESVELADA}

As intersignificações indicam que as temáticas formam um todo e possibilitam compreender, ao mesmo tempo, cada uma à luz das outras, constituindo, assim, uma trama onde os significados podem circular de acordo com os sentidos atribuídos, desvelando o fenômeno (RICOUER, 2006). Observamos que as intersignificações 
permitem que possamos adentrar o círculo hermenêutico no qual se dão; sendo círculo hermenêutico aqui caracterizado pela experiência na Oficina onde, primordialmente, a experiência é definida por meio das categorias, oriundas das descrições de cada sujeito participante e onde a aprendizagem da massagem (ação pedagógica da Oficina) só pode ser compreendida em relação à vivência experienciada por todos (ESPÓSITO, 1993) e possibilita compreender o sentido de ser dos profissionais e da estudante na experiência da Oficina, como o modo de cuidar dos modos de cuidar de seu fazer, de sua formação, de seu aprendizado, enfim de seu existir, expresso como um modo de empoderamento social para cuidar.

\section{CONSIDERAÇÕES FINAIS}

Os sentidos dados às experiências vividas na Oficina apontam perspectivas que nos auxiliam, tanto no desenvolvimento da capacidade de estabelecer relações humanas nos espaços profissionais, como na possibilidade de nos abrirmos a compartilhar essas experiências junto a outras que possamos construir em parcerias, situando nosso foco na dimensão sociopolítica dos vínculos afetivos, ainda hoje pouco compreendidos.

Reforçamos a importância de refletirmos sobre as diferentes formas de cuidado, buscando ir além das abordagens curativas, para valorizarmos o uso de tecnologias leves ou relacionais que favoreçam o cuidado humanizado, que possibilita segurança e fortalece as relações, podendo repercutir na aderência ao serviço, com melhores resultados à saúde da população.

Desse modo, vemos a massagem com bebês ser caracterizada como tecnologia leve voltada ao desenvolvimento humano, no sentido de possibilitar a otimização das relações profissionais junto aos familiares.

\section{REFERÊNCIAS}

AJURIAGUERRA, J. Manual de psiquiatria infantil. 2. ed. São Paulo: Masson, 1985.

BICUDO, M. A. V.; ESPÓSITO, V. H. C. (Orgs.). Pesquisa qualitativa em educação: um enfoque fenomenológico. 2. ed. Piracicaba: Editora UNIMEP, 1997.

BRASIL. Ministério da Saúde. Portaria no 849, de 27 de março de 2017: Inclui a Arteterapia, Ayurveda, Biodança, Dança Circular, Meditação, Musicoterapia, Naturopatia, Osteopatia, Quiropraxia, Reflexoterapia, Reiki, Shantala, Terapia Comunitária Integrativa e Yoga à Política Nacional de Práticas Integrativas e Complementares. Práticas Integrativas e Complementares. Disponível em: < http://189.28.128.100/dab/docs/portaldab/documentos/prt_849_27_3_2017.pdf >. Acesso em: 18 nov. 2017.

BRASIL. Lei $\mathbf{n}^{\mathbf{0}}$ 13.257, de 8 de março de 2016: Dispõe sobre as políticas públicas para a primeira infância. Disponível em: < http://www.planalto.gov.br/ccivil_03/_ato2015-2018/2016/lei/113257.htm >. Acesso em: 18 nov. 2017.

BRASIL. Ministério da Saúde. Resolução $\mathbf{n}^{\circ}$ 466, de 12 de dezembro de 2012: Diretrizes e normas regulamentadoras de pesquisa envolvendo seres humanos. Disponível em: < http://bvsms.saude.gov.br/bvs/saudelegis/cns/2013/res0466_12_12_2012.html >. Acesso em: 18 nov. 2017.

BRASIL. Guia prático de matriciamento em saúde mental. Brasília, DF: Ministério da Saúde/Centro de Estudo e Pesquisa em Saúde Coletiva, 2011.

BRAZELTON, T. B. O que todo bebê sabe. São Paulo: Martins Fontes, 1992.

BUSNEL, M. C. (Org.). A linguagem dos bebês. Sabemos escutá-los? São Paulo: Editora Escuta, 1997. 
CRITELLI, D. M. Analítica do sentido: uma aproximação e interpretação do real de orientação fenomenológica. São Paulo: EDUC Brasiliense, 2006.

CUNHA, M. Z. Criança e linguagem: um ensaio preliminar. 1997. Dissertação (Mestrado em Comunicação e Semiótica) - Programa de Comunicação e Semiótica, Pontifícia Universidade Católica de São Paulo, São Paulo, 1997.

ESPÓSITO, V. H. C. As confluências entre o pensamento de Merleau-Ponty e Paulo Freire. In: SEMINÁRIO EDUCAÇÃO. SABERES E IDENTIDADES: POVOS, CULTURA E EDUCAÇÕES, 2016, Cuiabá. Anais... Cuiabá, 2016.

ESPÓSITO, V. H. C. A formação como ação educativa: buscando sentidos. In: SILVA, G. T. R.; ESPÓSITO, V. H. C. (Orgs.). Educação e saúde: cenários de pesquisa e intervenção. São Paulo: Martinari, 2011. p. 25-48.

ESPÓSITO, V. H. C. Construindo o conhecimento da criança/adulto. Uma perspectiva interdisciplinar. São Paulo: Martinari, 2006.

ESPÓSITO, V. H. C. Hermenêutica. In: FAZENDA, I. Dicionário em construção: interdisciplinaridade. São Paulo: Cortes, 2001. p. 238-241.

ESPÓSITO, V. H. C. A escola: um enfoque fenomenológico. São Paulo: Editora Escuta, 1993.

FMCSV. Fundação Maria Cecilia Souto Vidigal. O que é parentalidade? Disponível em: < http://www.fmcsv.org.br/pt-br/sobre-nos/Paginas/O-que-\%C3\%A9-Parentalidade.aspx >. Acesso em: 18 nov. 2017.

FONTANELlA, F.; SPECK, F. P.; PIOVEZAN, A. P.; KULKAMP, I. C. Conhecimento, acesso e aceitação das práticas integrativas e complementares em saúde por uma comunidade usuária do Sistema Único de Saúde na cidade de Tubarão/SC. Arquivos Catarinenses de Medicina, v. 36, n. 2, p. 69-74, 2007. Disponível em: < http://www.acm.org.br/revista/pdf/artigos/484.pdf >. Acesso em: 18 nov. 2017.

FREIRE, P. Pedagogia da autonomia: saberes necessários à prática educativa. 28. ed. Rio de Janeiro: Paz e Terra, 2003.

FREIRE, P. Educação e atualidade brasileira. 1959. Tese (Doutorado) - Universidade Federal do Recife, Pernambuco, 1959.

GENESI, B. P. Massagem com bebês na perspectiva da mãe primípara: um ritual amoroso de aprendizagem mútua, disseminador de uma cultura de paz. 2014. Trabalho de Conclusão de Curso (Graduação em Enfermagem) - Universidade Federal de São Paulo, 2014.

HEIDEGGER, M. Ser e Tempo. Petrópolis: Vozes, 1998.

LA PLANCHE, J. Vocabulário da psicanálise. São Paulo: Martins Fontes, 1992.

LlagunO, N. S.; OliveirA, E. A.; ROSA, L. S. L.; SilVA, M. G. B.; ESPÓSITO, V. H. C. Capacidades humanas dos bebês em revelar-se na unidade neonatal. ENCONTRO DE ENFERMAGEM NEONATOLÓGICA, 3., 2016, São Paulo. Anais... São Paulo: UNIFESP, 2016.

MARTINS, J. Um enfoque fenomenológico de currículo. Currículo como poíesis. Organização de Vitória H. C. Espósito. São Paulo: Cortez, 1992.

MARTINS, J.; BICUDO, M. A. V. A pesquisa qualitativa em psicologia: fundamentos e recursos básicos. 2. ed. São Paulo: Moraes Ltda., 1994.

NARDO, L. R. O.; SILVA, S. S.; MARIN, M. J. S. Massagem Shantala - Uma revisão integrativa. Atas do Congresso Ibero Americano em Investigação Qualitativa, v.3, p. 273-278, 2014. Disponível em: < https://proceedings.ciaiq.org/index.php/CIAIQ/article/view/484/479 >. Acesso em: 18 nov. 2017. 
NASR, E. M. B.; SILVA, M. G. B.; NAGATA, M. F. A.; COTTA, M. L. A.; LUZ, C. B. S.; HURUTA, O. K. Grupos de Shantala, como prática integrativa e complementar nas Unidades Básicas de Saúde de São José dos Campos - SP. CONGRESSO PAULISTA DE SAÚDE PUBLICA, 15.; CONGRESSO DE SAÚDE PUBLICA NÚCLEO VALE DO PARAÍBA E LITORAL NORTE, 2018, Taubaté Anais... Taubaté, 2018.

OLIVEIRA, L. M.; SILVA, M. G. B. Conhecendo as reações dos lactentes ao serem massageados por suas mães. Revista da Sociedade Brasileira de Enfermeiros Pediatras, v. 3, n. 2, p. 109-120, 2003. PUCCINI, P. T.; CECÍlIO, L. C. O. A humanização dos serviços e o direito à saúde. Cadernos de Saúde Pública, v. 20, n. 5, 1342-1353, 2004.

RICOUER, P. Hermenêutica bíblica. São Paulo: Ed. Loyola, 2006.

RICOUER, P. O discurso da ação. Lisboa: Edições 70, 1988.

RONDON FILHO, F. Metodologia científica. Programa Treinee jul. 2010. Disponível em: < https://programatraineegrupocanopus.files. wordpress.com/2010/07/roteiro-de-estudo-metodologiacientifica.pdf >. Acesso em: 18 nov. 2017.

SAITO, C. M.; SILVA, M. G. B.; ESPÓSITO, V. H. C. A motricidade do bebê lactente em situação de massagem. COLÓQUIO DE PESQUISA QUALITATIVA EM MOTRICIDADE HUMANA: AS LUTAS NO CONTEXTO DA MOTRICIDADE, 4., 2009, São Carlos. Anais... São Carlos: SPQMH, 2009.

SBP. Sociedade Brasileira de Pediatria. Os 10 passos para a atenção hospitalar humanizada à criança e ao adolescente. Rio de Janeiro: SBP, 2003.

SHORE, R. Repensando o cérebro. Porto Alegre: Mercado Aberto, 2000.

SILVA, G. T. R.; ESPÓSITO, V. H. C. (Orgs.). Educação e saúde: cenários de pesquisa e intervenção. São Paulo: Martinari, 2011.

SILVA, M. G. B. Os sentidos das experiências vividas no programa de extensão massagem e estimulação com bebês. 2017. Tese (Doutorado em Ciências) - Escola Paulista de Enfermagem, Universidade Federal de São Paulo, São Paulo, 2017.

SILVA, M. G. B.; ESPÓSITO, V. H. C. Tempo bem vivido na experiência da oficina de massagem com bebês: desvelando sentidos. In: COLÓQUIO DE PESQUISA QUALITATIVA EM MOTRICIDADE HUMANA: ECOMOTRICIDADE E BEM VIVER, 7., 2017, Aracaju; São Cristóvão. Anais... São Carlos: SPQMH, 2017. p. 448-459.

SILVA, M. G. B.; ESPÓSITO, V. H. C. Massagem em bebês como ação educativa. In: SILVA, G. T. R.; ESPÓSITO, V. H. C. (Orgs.). Educação e saúde: cenários de pesquisa e intervenção. São Paulo: Martinari, 2011. p. 93-101.

SILVA, M. G. B.; ESPÓSITO, V. H. C.; OHARA, C. V. S. Pedagogia social de cuidado à criança: ação socioeducativa com graduandos no Programa de Extensão Massagem e Estimulação com Bebês (MEB). SEMINÁRIO INTERNACIONAL DE PESQUISA NO ENSINO DA SAÚDE DO CEDESS, 6.; ENCONTRO PRÓ-ENSINO NA SAÚDE, 4., 2014, São Paulo. Anais... São Paulo: UNIFESP, 2014.

SILVA, M. G. B.; SAITO, C. M.; ESPÓSITO, V. H. C.; OHARA, C. V. S. Intervenção educativa junto a mãe/bebê lactente em situação de massagem. In: COLÓQUIO DE PESQUISA QUALITATIVA EM MOTRICIDADE HUMANA: ETNOMOTRICIDADES DO SUL, 6., 2015, Valdivia, Chile. Anais... São Carlos: SPQMH, 2015. p. 424-438.

SILVA, M. G. B.; ESPÓSITO, V. H. C.; OHARA, C. V. S. Os sentidos da docência na docência da enfermagem pediátrica. SEMINÁRIO INTERNACIONAL DE PESQUISA NO ENSINO DA SAÚDE DO CEDESS, 6.; ENCONTRO PRÓ-ENSINO NA SAÚDE, 4., 2014, São Paulo. Anais... São Paulo: UNIFESP, 2014. 
Maria das Graças B. da Silva; Vitória Helena C. Espósito

STERN, D. O mundo interpessoal do bebê: uma visão a partir da psicanálise e da psicologia do desenvolvimento. Porto Alegre: Artes Médicas, 1992.

TAFURI, D. M.; GONÇALVES JUNIOR, L. Fundamentos teórico-conceituais da pesquisa em práticas sociais e processos educativos. Educação Unisinos (online), v. 21, p. 40-49, 2017.

TAVARES, V. R.; MUNIZ, J. C.; KISELAR, B.; OHARA, C. V. S.; ESPÓSITO, V. H. C.; SILVA, M. G. B. O sentido da experiência de monitoria no Programa de Extensão Massagem e Estimulação com Bebês (MEB). CONGRESSO ONLINE - GESTÃO, EDUCAÇÃO E PROMOÇÃO DA SAÚDE, 5., 2016. Anais... Congresso Virtual Brasileiro, 2016.

VAL, M. G. C. Redação e textualidade. São Paulo: Martins Fontes, 2006.

VAN MANEN, M. Investigación educativa y experiencia vivida. Ciencia humana para una pedagogía de la acción y la sensibilidad. Barcelona: Idea Books S.A., 2003.

WEIZZFLOG, W. (Org.). Michaelis: moderno dicionário da língua portuguesa. São Paulo: Melhoramentos, 2004.

WHO. Word Health Organization. Tradicional Medicine Strategy. Genebra, 2004. Disponível em: < http://www.who.int/medicines/areas/traditional/definitions/en/ >. Acesso em: 11 out. 2016.

Recebido em: 29 mar. 2018.

Aprovado em: 26 abr. 2018. 